\title{
Winners and Losers in a World with Global Warming: Noncooperation, Altruism, and Social Welfare.
}

Arthur J. Caplan Department of Economics, Weber State University, Ogden, UT 84408-3807
Christopher J. Ellis Department of Economics, University of Oregon, Eugene, OR 97403-1285

Emilson C. D. Silva

Department of Economics, University of Oregon, Eugene, OR 97403-1285

June 22, 1998 


\begin{abstract}
In this paper, global warming is an asymmetric transboundary externality which benefits some countries or regions and harms others. We use a simple two-country model to analyze the effects of global warming on resource allocations, the global-warming stock, and national and global welfare.
\end{abstract}

JEL: C72, D62, and H21. 


\section{1. Introduction.}

Few environmental problems have captured the public's imagination and attracted as much scrutiny as global warming. The general perception is that global warming is a net social bad, and that across-the-board abatement of greenhouse gas emissions is therefore desirable. Despite many interesting academic contributions, not all of the basic economics of this phenomenon have been fully worked out. The objective of this paper is to add to this basic understanding by developing a simple steady-state autarchy model to analyze the implications of greenhouse gas emissions for social (i.e., global) welfare.

Beginning with the Intergovernmental Panel on Climate Change's (IPCC's) first series of reports in 1990, the scientific debate over the greenhouse effect has slowly converged toward a consensus on four key points. First, the planet's mean surface temperature has steadily risen since the turn of the century. Second, anthropogenic sources, such as combustion of fossil fuels, are the primary contributors to this effect. Third, even if humanity abruptly converts to environmentally-benign sources of energy, such as solar and wind power, the earth is committed to increased warming during the 21st century. Fourth, the effects of global warming over the next century will vary by region. ${ }^{1}$

Previous work has recognized that global warming is an asymmetric transboundary externality and has concentrated on the international allocation of abatement costs. The commonly held hypothesis has been what might be described as the "lose-lose" scenario, in which every country is assumed to be harmed by global warming. ${ }^{2}$ Sandler [18] examines noncooperative games (leader-follower and Nash) where players' strategies are quantities of greenhouse gas emissions. He shows that if players' preferences over global warming abatement are consistent with the pure public good model, one obtains the well-known underprovision (of abatement) and neutrality results. But, if players' preferences are consistent with the impure public good model, as when emissions cause regional-specific as well as global damage, neutrality need not hold. This has profound implications for the global warming prob-

\footnotetext{
${ }^{1}$ For example, higher latitudes may in general experience warmer winters, while lower latitudes may expect drier summers (IPCC [8],[9]; Parry[17]).

${ }^{2}$ International agreements such as the 1993 summit in Rio de Janero, and the United Nations framework conventions (see Feldman [5] and Schelling [20]) bear witness to this point of view.
} 
lem, since the set of emitters of greenhouse gases is composed of both rich and poor nations.

Simulations carried out using general circulation models, however, frequently predict that a "win-lose" scenario may occur, whereby a group of nations, or regions within nations, actually benefit from global warming while others are hurt. Typically, the sector driving this result is agriculture. ${ }^{3}$ Winner regions are primarily located at middle and high latitudes, such as northern Japan, Northern Europe, Saskatchewan, and the central Ural mountains (Easterling, et. al. [4]). ${ }^{4}$ Loser regions include marginal agricultural lands located near the equator in Africa, as well as the bread-basket Corn Belt of the US., ${ }^{5}$ and nations heavily dependent on coastal agricultural zones, such as Bangladesh. ${ }^{6}$ With the exception of Martin et. al. [10], the "win-lose" scenario has been neglected by theorists - yet, it has profound implications. If global warming actually benefits some regions or countries, across-theboard abatement may not be socially desirable. Furthermore, whatever the desirable level of the greenhouse gas stock, countries will have an incentive to act strategically in choosing their own emissions levels. ${ }^{7}$ Countries that benefit from global warming will behave very differently from those that are harmed. For example, some countries' behavior towards fuel subsidization suggests widely disparate incentives. ${ }^{8}$ It is thus useful to investigate the basic economics of the win-lose scenario.

Our analysis of the asymmetric effects of global warming is deliberately simple. In our two-country model, there is no trade, no capital, and labor

\footnotetext{
${ }^{3}$ Gains in agriculture may be due to enhanced $\mathrm{CO}_{2}$ fertilization of $\mathrm{C} 3$ grain crops, longer growing seasons and higher water-use efficiency (Easterling, et. al [4], Parry [17]).

${ }^{4}$ Mendelsohn, Nordhaus and Shaw [12] argue that global warming may be slightly beneficial to US agriculture.

${ }^{5}$ Net losses in productivity may occur due to reduced water-use efficiency, and the higher risk of extended drought periods (Easterling, et. al. [4], Parry [17]).

${ }^{6}$ Agricultural losses may be due to rising sea levels, although some general circulation models predict that sea levels will actually fall due to polar ice cap expansions.

${ }^{7}$ Recent empirical evidence (Murdoch and Sandler [14] Murdoch, Sandler and Sargent [15] indicates that international emissions reduction agreements such as the Helsinki, Montreal and Sofia protocols did not impose any new constraints on their signatories. They served to legitimize the strategically chosen status quo.

${ }^{8}$ Many OECD coutries have adopted national $\mathrm{CO}_{2}$ abatement plans but then continue to subsidize the consumption of fossil fuels (Hoeller and Coppel [7]). The subsidization of coal, oil, and natural gas also occurs in several less developed countries (Shah and Larsen $[22])$.
} 
is internationally immobile. ${ }^{9}$ The transboundary externality is the only link between the two countries. We consider different assumptions about the degree of internalization of the global warming externality and examine the implications for national resource allocations and welfare levels. Specifically, we analyze the cases of full decentralization (or zero internalization), partial internalization (where the national effects of the externality are internalized, but its transboundary characteristic is ignored), full internalization or altruism (where the externality is fully internalized), and the various combinations of these possibilities that may occur if the behavioral regimes of the countries differ.

Our results are quite striking. We find that the winner country's greenhouse gas emissions are positively related to the losers, but that the loser's are negatively related to the winner's. With full decentralization, the equilibrium achieves allocative efficiency (constrained social efficiency); specifically, for a given level of the greenhouse gas stock, social welfare is maximized. Except for the fully altruistic equilibrium, the level of the greenhouse stock is generally not efficient. In each case, however, we show how the allocation deviates from constrained social efficiency.

From a policy perspective our analysis teaches us two important lessons. First, countries may voluntarily implement the socially optimal allocation if they behave altruistically. Given the potential for a multiplicity of equilibria with altruistic behavior, this is a reassuring result. Second, even if the socially optimal level of greenhouse gas cannot be identified or agreed upon, we can still characterize agreements on international reallocations of current emissions levels - i.e., emissions swaps - that are welfare improving.

\section{2. The Model.}

Imagine a world consisting of two countries indexed $i=1,2$. Each country is assumed to be populated by a representative agent (whose labor is internationally immobile) and governed by a benevolent government. Each agent chooses to allocate a fixed labor supply between the production of two private consumption goods, $x$ and $y$. This an autarchy model, where each agent consumes their own production. Good $x$ is an industrial good whose production emits greenhouse gases. Greenhouse gases, in turn, cause

\footnotetext{
${ }^{9} \mathrm{Or}$ we can think of coalitions of countries, where the countries within the coalition are identical (Copeland and Taylor [3]).
} 
a nonexcludable and nonrivalrous stock of global warming $G$. Good $y$ is an agricultural good whose production in the two countries is asymmetrically affected by the global warming externality. Agricultural productivity is affected negatively in country 1 and positively in country 2. The level of global warming depends on the stock of the greenhouse gas which is assumed to depend on the rate of emissions from industrial production and the rate of natural absorption (primarily by the oceans) according to the differential equation

$$
\dot{G}=h \sum x_{i}-n G
$$

where $n G$ is the natural rate of absorption of $\mathrm{CO}_{2}$ and $h$ translates the flow of aggregate industrial production into a flow of greenhouse gases. Without loss of generality, we assume that $h=n$, so that in a steady state $\sum x_{i}=G$. Henceforth, we shall limit our attention to these steady state solutions.

The representative agent living in country $i$ derives the following utility from consumption of the private goods:

$$
U_{i}=U\left(x_{i}, y_{i}\right)=V\left(x_{i}\right)+R\left(y_{i}\right)
$$

where we assume that $V($.$) and R($.$) are increasing, continuous, and strictly$ concave functions. Furthermore, $\frac{\partial V\left(x_{i}\right)}{\partial x_{i}} \rightarrow \infty$ as $x_{i} \rightarrow 0, \frac{\partial R\left(y_{i}\right)}{\partial y_{i}} \rightarrow \infty$ as $y_{i} \rightarrow$ 0 . The agent maximizes utility by choosing an allocation of labor between production of the two goods according to the transformation function

$$
y_{i}=F_{i}\left(x_{i}, G\right)=T\left(x_{i}\right)+H_{i}(G)
$$

where $T($.$) , the private component of F_{i}$, is decreasing and strictly concave in $x_{i}$. Following Matcheck [11] and Mendelsohn et al. [12], we assume that the damage function $H_{i}$ is decreasing and strictly concave in $G$ for $i=1$, but increasing and linear for $i=2 .{ }^{10}$ The function $H_{i}(G)$ captures the external effect of global warming on industrial good production. As it seems reasonable, we make the further restriction that $\frac{\partial T\left(x_{2}\right)}{\partial x_{2}}+\frac{\partial H_{2}(G)}{\partial G} \frac{\partial G}{\partial x_{2}}<0$; that is, even when the effects of the externality are positive, production of both goods cannot rise simultaneously. Substituting the transformation function into the utility function yields

$$
U_{i}=V\left(x_{i}\right)+R\left(T\left(x_{i}\right)+H_{i}(G)\right)=V\left(x_{i}\right)+W_{i}\left(x_{i}, G\right)
$$

\footnotetext{
${ }^{10}$ There is much debate about the curvature of the damage function for winner countries. Our results are presented for the linear case; however, it can be shown that they always hold for the convex case and also in the concave case provided the curvature is not "too great".
} 
Note that $W_{i}\left(x_{i}, G\right)$ is strictly concave in both $x_{i}$ and $G$ for $i=1,2$.

In this simple structure, the only difference between the welfare of agents in the two countries arises as a consequence of the global warming externality. This allows us to focus exclusively on the fundamental effects of an asymmetric transboundary externality.

\section{3. Noncooperative Nash Equilibria.}

The solution to the representative agent's optimization problem involves maximizing (4), given the degree to which they are induced to internalize the global warming externality. The degree of internalization represents the choice variable of each government. The governments are assumed to possess marginal and lump sum tax instruments sufficient to achieve any desired output combination that balances the budget. There are three possible degrees of internalization required of each representative agent $i$ : (i) full decentralization (denoted $D_{i}$ ); (ii) internalization of the intraboundary component of the externality (denoted $P_{i}$ ); and (iii) full internalization of the externality (denoted $A_{i}$ ). Each of these possibilities can be characterized using the following "generic" pair of first order conditions: ${ }^{11}$

$$
\frac{\partial V\left(x_{i}\right)}{\partial x_{i}}+\frac{\partial W_{i}\left(x_{i}, G\right)}{\partial x_{i}}+\alpha_{0 i} \frac{\partial W_{i}\left(x_{i}, G\right)}{\partial G}+\alpha_{1 i} \frac{\partial W_{-i}\left(x_{-i}, G\right)}{\partial G}=0, \quad i=1,2
$$

If $\alpha_{0 i}=\alpha_{1 i}=0, i=1,2$ in (5), we have the standard first order conditions for representative agents who do not internalize any component of the externality - i.e., we have scenario $D_{1} D_{2}$. If $\alpha_{0 i}=1$, and $\alpha_{1 i}=0, i=1,2$, each representative agent is induced to internalize the intraboundary component of the externality, but not the transboundary one - i.e., we have scenario $P_{1} P_{2}$. If $\alpha_{0 i}=\alpha_{1 i}=1, i=1,2$, each representative agent is induced to internalize both components of the externality - i.e., we have scenario $A_{1} A_{2}$. In total, there are 16 possibilities (see table 1 below). We neglect those possibilities associated with the empty cells, because these represent situations where a country internalizes the transboundary component of the externality, but neglects the intraboundary component. We assume that no government is this altruistic. ${ }^{12}$

\footnotetext{
${ }^{11}$ These and subsequent expressions utilize $\frac{\partial G}{\partial x_{i}}=\frac{\partial G}{\partial x_{-i}}=1$.

${ }^{12}$ It has however been suggested by Murdoch, Sandler and Sargent [15] that the Sophia
} 


\begin{tabular}{ccccccc}
\hline & & \multicolumn{5}{c}{ Country \#1. } \\
\hline & & & \multicolumn{3}{c}{$\alpha_{01}=0$} & \multicolumn{2}{c}{$\alpha_{01}=1$} \\
& & & $\alpha_{11}=0$ & $\alpha_{11}=1$ & $\alpha_{11}=0$ & $\alpha_{11}=1$ \\
Country & $\alpha_{02}=0$ & $\alpha_{12}=0$ & D1D2 & - & P1D2 & A1D2 \\
$\# 2$. & & $\alpha_{12}=1$ & - & - & - & - \\
& \multirow{2}{*}{$\alpha_{02}=1$} & $\alpha_{12}=0$ & D1P2 & - & P1P2 & A1P2 \\
& & $\alpha_{12}=1$ & D1A2 & - & P1A2 & A1A2 \\
\hline
\end{tabular}

Table 1. Equilibrium Scenarios.

When one country is harmed and the other benefits from an externality, it is no longer clear how the characteristics of the various noncooperative equilibria will compare. ${ }^{13}$ We investigate how the global warming externality affects resource allocations across the various noncooperative equilibria. Each equilibrium may be defined by the intersection of reaction functions given by the solutions to the appropriate first order conditions. We shall later compare the noncooperative equilibria with the utilitarian social welfare optimum.

\subsection{1. Pure Decentralization.}

This is the situation where each representative agent treats $G$ as a constant - i.e., scenario $D_{1} D_{2}$. The first order conditions define a pair of reaction functions

$$
x_{i}^{D}=X_{i}^{D}\left(x_{-i}\right) \quad i=1,2
$$

whose slopes are given by ${ }^{14}$

$$
\frac{d X_{i}^{D}}{d x_{-i}}=-\frac{\frac{\partial^{2} W_{i}}{\partial x_{i} \partial G}}{\frac{\partial^{2} V}{\partial x_{i}^{2}}+\frac{\partial^{2} W_{i}}{\partial x_{i}^{2}}}
$$

It is easy to show that $-1<\frac{d X_{1}^{D}}{d x_{2}}<0$ and $0<\frac{d X_{2}^{D}}{d x_{1}}<1$.

Protocol does potentially generate the case where $\alpha_{o i}=0$ and $\alpha_{1 i}=1 i=1,2$ - i.e. only the transboundry component of an externality (e.g., acid rain) may be internalized.

${ }^{13} \mathrm{We}$ do not provide a formal existence proof for each possible equilibrium. Given the assumptions of the model, existence is not problematic. Existence proofs are available from the authors upon request.

${ }^{14}$ Follows from $\frac{\partial^{2} V}{\partial x_{i}^{2}}<0$ for both $i=1,2, \frac{\partial^{2} W}{\partial x_{i}^{2}}=\frac{\partial^{2} R}{\partial y_{i}^{2}}\left[\frac{\partial T}{\partial x_{i}}+\frac{\partial H_{i}}{\partial G}\right] \frac{\partial T}{\partial x_{i}}+\frac{\partial R}{\partial y_{i}} \frac{\partial^{2} T}{\partial x_{i}^{2}}<0$ for both $i=1,2$ since $\frac{\partial T}{\partial x_{i}}+\frac{\partial H_{i}}{\partial G}<0$, and $\frac{\partial^{2} W}{\partial x_{i} \partial G}=\frac{\partial^{2} R}{\partial y_{i}^{2}} \frac{\partial H_{i}}{\partial G} \frac{\partial T}{\partial x_{i}} \lessgtr 0$ as $i=1,2$. 


\subsection{2. Partial Internalization.}

When a domestic government intervenes in its economy, it can choose to induce its agent to internalize the intraboundary component of the externality only or to internalize both components of the externality. Here, we consider partial internalization - each country internalizes only the intraboundary component. Its optimization problem yields the first order condition (5) with $\alpha_{0 i}=1$ and $\alpha_{1 i}=0$. This defines a new reaction function for representative agent $i$ written

$$
x_{i}=X_{i}^{P}\left(x_{-i}\right)
$$

The slopes of the reaction functions are given by ${ }^{15}$

$$
\frac{d X_{i}^{P}}{d x_{-i}}=-\frac{\frac{\partial^{2} W_{i}}{\partial x_{i} \partial G}+\frac{\partial^{2} W_{i}}{\partial G^{2}}}{\frac{\partial^{2} V}{\partial x_{i}^{2}}+\frac{\partial^{2} W_{i}}{\partial x_{i}^{2}}+2 \frac{\partial^{2} W_{i}}{\partial x_{i} \partial G}+\frac{\partial^{2} W_{i}}{\partial G^{2}}}
$$

Inspection of the expressions above immediately reveals that $-1<\frac{d X_{1}^{P}}{d x_{2}}<0$. Comparing the reaction functions $X_{i}^{D}\left(x_{-i}\right)$ and $X_{i}^{P}\left(x_{-i}\right)$, we obtain:

$X_{1}^{P}\left(x_{2}\right)<X_{1}^{D}\left(x_{2}\right)$ for any given $x_{2}$, and $X_{2}^{P}\left(x_{1}\right)>X_{2}^{D}\left(x_{1}\right)$ for any given $x_{1 .}$

Consider any feasible arbitrary constant $x_{-i}$ and define as $x_{i}^{D}$ and $x_{i}^{P}$ the solutions to (6) and (7) given $x_{-i}$. We know that $\frac{\partial V\left(x_{i}^{D}\right)}{\partial x_{i}}+\frac{\partial W_{i}\left(x_{i}^{D}, G\right)}{\partial x_{i}}=$ $\frac{\partial V\left(x_{i}^{P}\right)}{\partial x_{i}}+\frac{\partial W_{i}\left(x_{i}^{P}, G\right)}{\partial x_{i}}+\frac{\partial W_{i}\left(x_{i}^{P}, G\right)}{\partial G}=0$. Since $\frac{\partial W_{1}\left(x_{1}^{P}, G\right)}{\partial G}<0$ and $\frac{\partial W_{2}\left(x_{2}^{P}, G\right)}{\partial G}>0$, we have $\frac{\partial V\left(x_{1}^{D}\right)}{\partial x_{1}}+\frac{\partial W_{1}\left(x_{1}^{D}, G\right)}{\partial x_{1}}<\frac{\partial V\left(x_{1}^{P}\right)}{\partial x_{1}}+\frac{\partial W_{1}\left(x_{1}^{P}, G\right)}{\partial x_{1}}$ and $\frac{\partial V\left(x_{2}^{D}\right)}{\partial x_{2}}+\frac{\partial W_{2}\left(x_{2}^{D}, G\right)}{\partial x_{2}}>$ $\frac{\partial V\left(x_{2}^{P}\right)}{\partial x_{2}}+\frac{\partial W_{2}\left(x_{2}^{P}, G\right)}{\partial x_{2}}$. The Proposition follows immediately from differentiation of the left hand side of each inequality above with respect to $x_{i}$, since $\frac{\partial^{2} V\left(x_{i}^{D}\right)}{\partial x_{i}^{2}}+$ $\frac{\partial^{2} W_{i}\left(x_{i}^{D}, G\right)}{\partial x_{i}^{2}}+\frac{\partial^{2} W_{i}\left(x_{i}^{D}, G\right)}{\partial x_{i} \partial G}<0$ for $i=1,2$.

Proposition 1 shows that industrial production under fully decentralized behavior is higher (lower) in country 1 (2) than under partially internalized behavior. While neither country recognizes the effects of their actions on the global externality under full decentralization, government 1 (2) induces each agent to reduce (increase) industrial production when it controls the intraboundary margin of the externality. Figure 1 illustrates the possible

\footnotetext{
${ }^{15}$ As the previous footnote demonstrated, the derivation of each reaction function's slope is a straightforward comparative statics exercise. We shall omit such derivations from this point on.
} 
combinations of equilibria. For ease of exposition, we utilize linear reaction functions; however, it should be clear from Proposition 1 that the specific shapes and slopes of the curves do not alter the relative locations of the equilibrium levels of industrial products, $x_{i}^{k j}, k=D, P, j=D, P{ }^{16}$

dtbpFU6.2621in4.3024in0ptFigure 1. Equilibria with Decentralization and Government Intervention.pic1.wmf

\subsection{3. Full Internalization: Altruistic Behavior.}

Suppose now that national governments are altruistic. They induce their agents to internalize both components of the externality. To date, there is virtually no example of a fully altruistic equilibrium (see the discussion in Sandler [19]). This equilibrium, however, is a useful benchmark. For each $i$, we have the first order condition (5) with $\alpha_{0 i}=1$ and $\alpha_{1 i}=1$. The pair of reaction functions are now written

$$
x_{i}=X_{i}^{A}\left(x_{-i}\right) \quad i=1,2
$$

The slopes of the reaction functions are given by

$$
\frac{d X_{i}^{A}}{d x_{-i}}=-\frac{\frac{\partial^{2} W_{i}}{\partial x_{i} \partial G}+\frac{\partial^{2} W_{i}}{\partial G^{2}}+\frac{\partial^{2} W_{-i}}{\partial G^{2}}+\frac{\partial^{2} W_{-i}}{\partial G \partial x_{-i}}}{\frac{\partial^{2} V}{\partial x_{i}^{2}}+\frac{\partial^{2} W_{i}}{\partial x_{i}^{2}}+2 \frac{\partial^{2} W_{i}}{\partial x_{i} \partial G}+\frac{\partial^{2} W_{i}}{\partial G^{2}}+\frac{\partial^{2} W_{-i}}{\partial G^{2}}}
$$

Although the signs of the reaction functions are indeterminate, we know that both have the same sign - the numerators are common and, by the second order conditions, the denominators are negative. We can still compare the altruistic and partial internalization cases by examining the relative locations of the two pairs of reaction functions $X_{i}^{A}\left(x_{-i}\right)$ and $X_{i}^{P}\left(x_{-i}\right), i=1,2$. We obtain:

$X_{1}^{P}\left(x_{2}\right)<X_{1}^{A}\left(x_{2}\right)$ for any given $x_{2}$, and $X_{2}^{P}\left(x_{1}\right)>X_{2}^{A}\left(x_{1}\right)$ for any given $x_{1 .}$

Consider an arbitrary constant $x_{-i}$ and let $x_{i}^{A}$ and $x_{i}^{P}$ denote the solutions to (6) and (7) given $x_{-i}$. We know that $\frac{\partial V\left(x_{i}^{A}\right)}{\partial x_{i}}+\frac{\partial W_{i}\left(x_{i}^{A}, G\right)}{\partial x_{i}}+\frac{\partial W_{i}\left(x_{i}^{A}, G\right)}{\partial G}+$ $\frac{\partial W_{-i}\left(x_{-i}^{A}, G\right)}{\partial G}=\frac{\partial V\left(x_{i}^{P}\right)}{\partial x_{i}}+\frac{\partial W_{i}\left(x_{i}^{P}, G\right)}{\partial x_{i}}+\frac{\partial W_{i}\left(x_{i}^{P}, G\right)}{\partial G}=0$. It follows that $\frac{\partial V\left(x_{i}^{A}\right)}{\partial x_{i}}+$

\footnotetext{
${ }^{16} \mathrm{By}$ Proposition 1, if the slopes of the reaction functions differ, then, $X_{2}^{D}\left(x_{1}\right)$ is steeper than $X_{2}^{P}\left(x_{1}\right)$ and $X_{1}^{P}\left(x_{2}\right)$ is steeper in absolute value than $X_{1}^{D}\left(x_{2}\right)$ over the ranges of $x_{i}, i=1,2$, considered here. Thus the respective reaction functions for each country cannot cross. This also ensures that $x_{1}^{P D} \leq x_{1}^{D P}$ and that $x_{2}^{D D} \leq x_{2}^{P P}$.
} 
$\frac{\partial W_{i}\left(x_{i}^{A}, G\right)}{\partial x_{i}}+\frac{\partial W_{i}\left(x_{i}^{A}, G\right)}{\partial G}<(>) \frac{\partial V\left(x_{i}^{P}\right)}{\partial x_{i}}+\frac{\partial W_{i}\left(x_{i}^{P}, G\right)}{\partial x_{i}}+\frac{\partial W_{i}\left(x_{i}^{P}, G\right)}{\partial G}$, for $i=1(2)$. Differentiating the right hand side of each inequality with respect to $x_{i}$ yields $\frac{\partial V^{2}\left(x_{i}^{P}\right)}{\partial x_{i}^{2}}+\frac{\partial^{2} W_{i}\left(x_{i}^{P}, G\right)}{\partial x_{i}^{2}}+2 \frac{\partial^{2} W_{i}\left(x_{i}^{P}, G\right)}{\partial x_{i} \partial G}+\frac{\partial^{2} W_{i}\left(x_{i}^{P}, G\right)}{\partial G^{2}}<0$ for $i=1,2$. For $i=1$, the sign follows trivially from the negativity of each of the terms. For $i=2$, the sign follows from concavity of $W_{i}\left(x_{i}, G\right)$. The expressions above imply the statement of the Proposition.

Figure 2 illustrates reaction functions for the government intervention and altruistic cases.dtbpFU5.4388in4.4676in0ptFigure 2. Equilibria with Government Intervention and Altruism.picn2.wmf

Industrial production under altruism in country 1 (2) is always higher (lower) than under partial internalization. With partial internalization, country 1 (2) does not recognize the positive (negative) spillover effect of the externality and consequently produces less (more) of the industrial output than it does when it fully accounts for the spillover effect. Proposition $2 \mathrm{im}-$ plies that neither country's altruistic and government-intervention reaction functions can intersect. We shall assume henceforth that either country's altruistic reaction function slopes upward. In Figure 2, the reaction functions have variable slopes but the slopes do not change their signs.

In Figures 1 and 2, all possible equilibrium outcomes are stable. Stability requires that the slope of the appropriate reaction function $\mathrm{D}$ or $\mathrm{P}$ for country 2 exceeds the absolute slope of the appropriate reaction function for country 1 . Since for country 1 the slopes of the reaction functions are strictly between 0 and -1 , a sufficient condition for stability is that, at the points of intersection, the slopes of the reaction functions for country 2 are greater than the slopes of the reaction functions for country 1. Formally, the conditions are $1<\frac{d X_{2}^{k}\left(x_{1}\right)}{d x_{1}}, k=\{D, P\}$. We assume these conditions hold hereafter.

We wish now to investigate how the levels of industrial output and global warming are affected by the possible degrees of internalization of the externality. We begin with the levels of industrial production in the two countries. The implications of the preceding diagrams are summarized in the following Propositions: ${ }^{17}$

For the industrial production of country 1: $x_{1}^{D P}<\left\{x_{1}^{D D}, x_{1}^{D A}\right\}, x_{1}^{P P}<$ $\left\{x_{1}^{P D}, x_{1}^{D P}, x_{1}^{D D}, x_{1}^{A P}, x_{1}^{P A}, x_{1}^{A A}, x_{1}^{A D}, x_{1}^{D A}\right\}, x_{1}^{P D}<\left\{x_{1}^{D D}, x_{1}^{A D}\right\}, x_{1}^{D D} \gtreqless x_{1}^{A A}$.

For the industrial production of country 2: $x_{2}^{P D}<\left\{x_{2}^{P P}, x_{2}^{A P}, x_{2}^{D P}\right\}$,

\footnotetext{
${ }^{17}$ Proofs of these Propositions can be obtained from the authors upon request.
} 
$x_{2}^{D P}>\left\{x_{2}^{P P}, x_{2}^{P A}, x_{2}^{P D}, x_{2}^{D D}, x_{2}^{A A}, x_{2}^{A D}, x_{2}^{D A}\right\}, x_{2}^{A P}>\left\{x_{2}^{P P}, x_{2}^{P A}, x_{2}^{P D}\right\}$, $x_{2}^{P A}<\left\{x_{2}^{P P}, x_{2}^{A P}, x_{2}^{D P}\right\}$.

These results allow us to draw some conclusions about the relative levels of the greenhouse gas stock in the various equilibria.

For the level of global warming: $\left\{G^{P A}, G^{P D}\right\}<G^{P P}<\left\{G^{A P}, G^{D P}\right\}$, $\left\{G^{P A}, G^{A D}\right\}<G^{A A}<\left\{G^{A P}, G^{D A}\right\}, G^{P D}<\left\{G^{P P}, G^{D D}\right\}<G^{D P}$, $G^{D D} \lesseqgtr G^{A A} \lesseqgtr G^{P P}$.

Observe that relative to a situation without any governmental intervention, if country 1(2) partially internalizes the externality, the greenhouse gas stock falls (rises). These results follow because: (a) whenever country 1 's government, unilaterally, partially internalizes the externality, industrial production falls not only in that country, but also in country 2; and (b) whenever country 2's government, unilaterally, partially internalizes the externality, industrial production rises in that country by more than it falls in country 1 - remember that the reaction functions for country 1 have absolute slopes less than 1.

How much of the behavior of the greenhouse-gas-emitting nations does our framework explain? Presently, nations can be classified in one of three categories: (1) nations that explicitly implement abatement policies; (2) nations that implicitly follow policies that yield increased production of greenhouse gases; and (3) nations that announce, but do not implement, abatement policies. The Scandinavian countries and the Netherlands seem to fall in category 1. Over the past several years, Finland has levied a per-ton tax on the carbon content on non-transport fuels. This is in addition to similar taxes on transport fuels which had been instituted beforehand (Schmidt, [21]; Haugland, et. al., [6]). In February of 1990, the Netherlands also instituted a small $\mathrm{CO}_{2}$ tax, primarily to raise revenue for conservation measures. This tax was levied in addition to existing excise and environmental taxes (Ibid). Such behavior can be interpreted in one of two ways. Either these countries view themselves as potential losers who are concerned with internalizing the intraboundary component of the externality only, or they view themselves as altruistic winners (which some studies suggest they may be).

Japan, Germany, Britain, China, the former USSR, India, and Mexico appear to be good examples of countries in category 2. The first three countries subsidize their coal industries, while all others subsidize consumption of coal, oil, and natural gas (Hoeller and Coppel, [7]; Shah and Larsen, [22]). In our framework, these countries would be classified as either prospective winners (again as suggested by some studies), who internalize the intrabound- 
ary component, or as losers who behave altruistically (a feasible yet unlikely prospect). These nations may, alternatively, be behaving in a decentralized way. The implicit subsidies seem to be the result of consumer pressure more than the governments' concern with global warming.

The remaining OECD countries seem to fall in category 3. Even though most of these nations have greenhouse-gas-emission targets, few have aggressively tried to achieve them (Schmidt, [21]; Climate Network Europe, et. al., [1]). For example, Australia and Canada have adopted national $\mathrm{CO}_{2}$-reduction plans, but they are reluctant to consider their unilateral implementation. Greece, Luxembourg (which has the highest per-capita $\mathrm{CO}_{2}$ emissions among OECD countries), Portugal, and Spain have made no unilateral commitments on emissions, even though they each have agreed to the European Community (EC) target of $\mathrm{CO}_{2}$ stabilization (Ibid). In our framework, these nations are characterized by decentralized behavior.

Our comparisons of equilibria appear to shed some light on actual national policies, but they do not tell us anything about the social (i.e., global) desirability of the equilibrium outcomes. To examine this issue, we need to contrast them with the socially optimal allocation.

\section{4. Social Welfare.}

Before we make welfare comparisons among equilibria, we must characterize the social welfare optimum. Suppose there exists a benevolent and utilitarian social planner endowed with sufficient political and economic powers to implement any desired allocation. Maximal social welfare is defined by

$$
x_{i} \operatorname{Max} S=\sum_{i} V\left(x_{i}\right)+\sum_{i} W_{i}\left(x_{i}, G\right)
$$

The socially optimal allocation is the solution to the following first order conditions:

$$
\frac{\partial V\left(x_{i}\right)}{\partial x_{i}}+\frac{\partial W_{i}\left(x_{i}, G\right)}{\partial x_{i}}+\frac{\partial W_{i}\left(x_{i}, G\right)}{\partial G}+\frac{\partial W_{-i}\left(x_{-i}, G\right)}{\partial G}=0 \quad i=1,2 .
$$

These are the standard Samuelson conditions, which state that the marginal private value of another unit of industrial production in either country must 
equal the marginal damage/benefit (summed across both countries) of the implied additional greenhouse gas stock. ${ }^{18}$

Let $x_{i}^{*}, i=1,2$, denote the socially efficient levels of industrial production. The socially optimal level of the greenhouse stock, denoted $G^{*}$, is simply, $x_{1}^{*}+x_{2}^{*}=G^{*}$. It will prove useful in what follows to think of the social optimum as the allocation that arises from satisfaction of two conditions: (i) setting $G$ at $G^{*}$; and (ii) requiring that the individual contributions of the two countries to the greenhouse gas stock be "allocatively efficient." Such a division of tasks will enable us to better understand the global warming problem as well as to make some interesting observations about effective policy making.

\subsection{1. Allocative Efficiency.}

An allocation is said to be allocative efficient if it is the solution to the maximization of the social welfare function (9) with respect to $x_{i}, i=1,2$, subject to the constraint $x_{1}+x_{2}=\bar{G}$, where $\bar{G}$ is a fixed level of the greenhouse stock. An allocative efficient allocation is thus a constrained socially efficient allocation. It corresponds to the socially efficient allocation if and only if $\bar{G}=G^{*}$. As the greenhouse gas stock varies, the locus of allocatively efficient points is defined by the tangencies between constant social welfare contours and constant greenhouse gas stock constraints. Since the slope of the greenhouse gas constraint is -1 , the necessary condition for allocative efficiency is

$$
\frac{d x_{i}}{d x_{-i}}=-\frac{\frac{\partial V\left(x_{-i}\right)}{\partial x_{-i}}+\frac{\partial W_{-i}\left(x_{-i}, \bar{G}\right)}{\partial x_{-i}}+\frac{\partial W_{-i}\left(x_{-i}, \bar{G}\right)}{\partial G}+\frac{\partial W_{i}\left(x_{i}, \bar{G}\right)}{\partial G}}{\frac{\partial V\left(x_{i}\right)}{\partial x_{i}}+\frac{\partial W_{i}\left(x_{i}, \bar{G}\right)}{\partial x_{i}}+\frac{\partial W_{i}\left(x_{i}, \bar{G}\right)}{\partial G}+\frac{\partial W_{-i}\left(x_{-i}, \bar{G}\right)}{\partial G}}=-1
$$

which reduces to

$$
\frac{\partial V\left(x_{-i}^{S}\right)}{\partial x_{-i}}+\frac{\partial W_{-i}\left(x_{-i}^{S}, \bar{G}\right)}{\partial x_{-i}}=\frac{\partial V\left(x_{i}^{S}\right)}{\partial x_{i}}+\frac{\partial W_{i}\left(x_{i}^{S}, \bar{G}\right)}{\partial x_{i}}
$$

\footnotetext{
${ }^{18} \mathrm{It}$ is easy to see that the socially optimal allocation is interior and unique. The social welfare function is strictly concave in $x_{i}, i=1,2$, and our assumptions that $\frac{\partial V\left(x_{i}\right)}{\partial x_{i}} \rightarrow \infty$ as $x_{i} \rightarrow 0, \frac{\partial R\left(y_{i}\right)}{\partial y_{i}} \rightarrow \infty$ as $y_{i} \rightarrow 0$ guarantee that the social optimum involves nonzero levels for all choice variables.
} 
where $x_{i}^{S} i=1,2$, denotes an allocatively efficient pair for a given gas stock, $\bar{G}$. Intuitively, the condition says that to be allocatively efficient contributions to the greenhouse gas stock must be of equal private marginal value to both countries. Since (9) is strictly concave and the constraint is linear, there is only one point of tangency between a social indifference curve and the line defined by $x_{1}+x_{2}=\bar{G}$.

\subsection{2. Welfare Properties of the Equilibria.}

We shall now discuss the allocative efficiency properties of the various noncooperative equilibria. Focusing on allocative efficiency rather than social efficiency seems appropriate for four main reasons. First, there is too much uncertainty about which stock of greenhouse gas is socially optimal. Recent works that attempted to identify an optimal stock assert that their estimates are imprecise (Nordhaus, [16]; Cline, [2]). Second, international emissions reduction targets - such as those set forth in United Nations Framework Convention on Climate Change at the Rio Summit in 1992 - as well as the strengthening amendments recently promulgated in Bonn under the Berlin Mandate of 1995 establish a greenhouse gas stock which may be far from the socially optimal level. Third, our policy prescriptions based on allocative efficiency are clear and precise. Fourth, as we demonstrated above, allocative efficiency is a necessary condition for social optimality.

Since there are nine noncooperative equilibria, we shall avoid significant amounts of repetitive algebra by presenting our conclusions in a summary table. ${ }^{19}$

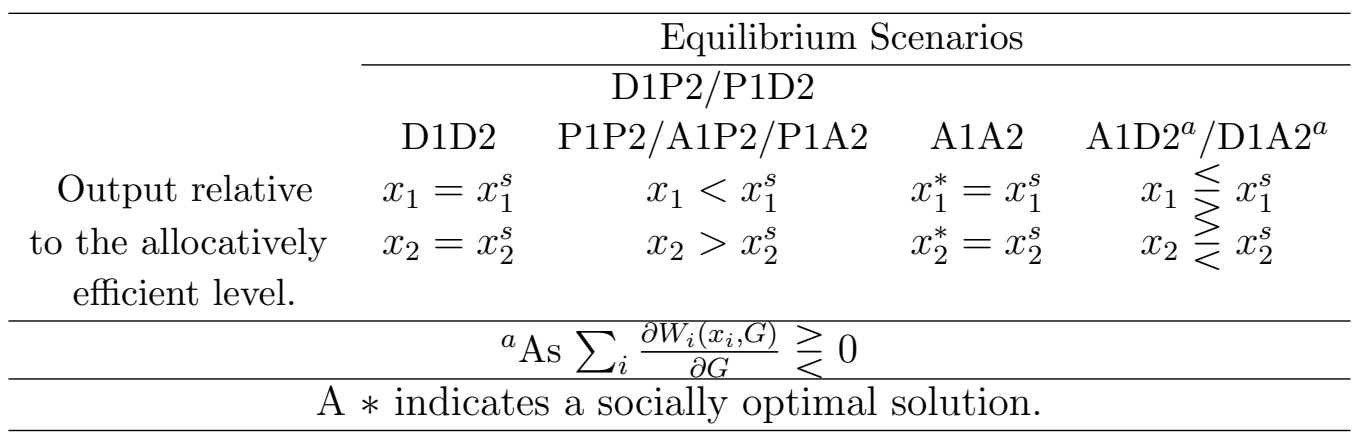

Table 2. Allocative Efficiency and Social Welfare.

\footnotetext{
${ }^{19}$ Full derivations for all the equilibria are available from the authors on request.
} 
We briefly discuss each of these results below.

The Decentralized Equilibrium D1D2.

As table 2 indicates, the decentralized equilibrium is allocatively efficient. In the decentralized equilibrium, each country neglects the effects of its own contribution to the externality and produces industrial output until the marginal value of doing so is zero (recall that the impact on agricultural output is included in this calculation). Hence, for $\bar{G}=G^{D D}$, the marginal values of the contributions to the externality of the two countries are equalized. ${ }^{20}$

Equilibria with government intervention D1P2, P1D2, and P1P2.

If a country induces the internalization of only the intraboundary component of the externality, the resulting equilibrium will violate allocative efficiency. If country 1(2) internalizes the domestic damage from the externality, it will reduce (increase) its industrial output. As a result, country 2 (1) will contribute too much (too little) to the externality in the sense of allocative efficiency.

Equilibria where one country is altruistic and the other engages in government intervention, A1P2 or P1A2.

This result is intuitive. If only the intraboundary component of the externality is internalized, the loser country has an incentive to under emit while the winner country has an incentive to over emit. The fact that the altruistic country also internalizes the transboundary component does not significantly mitigate the problem. If the loser under emits, an altruistic winner's response induces the loser to emit more (see figure 2), but the marginal value of increased emissions to the loser is small. Also, if the winner over emits, an altruistic loser actually emits more, which induces the winner to emit even further (see figure 2).

Equilibria where one country is altruistic and the other decentralized, D1A2 and A1D2.

If, at the margin, the positive effects of the transboundary components of the externality outweigh the negative effects, then from an allocative perspective the altruistic country will produce too much of the industrial good, while the decentralized country will produce too little. If, at the margin, the

\footnotetext{
${ }^{20}$ The allocation, however, is not socially efficient because it violates the Samuelson conditons (10). From Proposition 5, we know that $G^{A A}<G^{D D}$. Note that $G^{A A}=$ $G^{*}$, since if both countries are altruistic, the conditions that characterize the equilibrium correspond to the Samuelson conditions (10).
} 
negative effects of the transboundary components of the externality outweigh the positive effects, then the altruistic country will produce too little of the industrial good, while the decentralized country will produce too much. In either case, allocative efficiency fails due to the overesponse of the altruistic government.

\section{The Fully Altruistic Equilibrium, A1A2.}

The fully altruistic equilibrium is socially efficient, because the conditions that characterize this equilibrium correspond to the Samuelson conditions (10). Hence, $G^{A A}=G^{*}$. It also follows that this equilibrium is unique, since the socially efficient allocation is unique.

Note that we obtain allocative efficiency only in two of the nine equilibria. If we "move" from the decentralized equilibrium to some other equilibrium, we will generally lose allocative efficiency. In particular, a movement from the decentralized allocation to an allocation with a single altruistic country will fail to yield allocative efficiency. This tells us that a little altruism is not necessarily welfare improving - a cautionary note for countries that display the desire to unilaterally adopt altruistic policies. This suggests that the wellintentioned greenhouse gas abatement policies of some Northern European nations may well be counterproductive - a laissez faire approach might be superior. Finally, it is also interesting to note that the only other instance where allocative efficiency is satisfied is when both countries are endowed with altruistic preferences, a set of incentives which is at complete odds with the selfish incentives that characterize the decentralized equilibrium.

\subsection{3 Potential Implications for International Policy Agreements.}

In the scenarios characterized by allocative inefficiency we generally have the result that $x_{1}<x_{1}^{s}$ and $x_{2}>x_{2}^{s}$; that is, the country that benefits from global warming over emits while the country harmed under emits. This inefficiency arises because internalizing the intraboundary portion of the externality induces a reallocation of resources into the externality producing sector for the winner country and out of that sector for the loser. Precisely because of the externality, the non-externality producing sector becomes relatively more productive for the winner and relatively less productive for the loser. This raises an interesting possibility for international policy agreements. Countries can potentially agree to Pareto improving emissions swaps. If country 1 
were to increase its emissions by one unit while country 2 were to decrease its emissions by a unit, each country would be better off and the stock of greenhouse gas would be unaffected. Hence, without having to solve the problem of whether the gas stock is above or below its optimum, we can always find welfare improving agreements. ${ }^{21}$ This illustrates the importance of allocative efficiency as a welfare criteria in this type of problem.

It is important to note that in some dimensions reciprocal changes in greenhouse gas emissions are similar to transfers. If a country fails to adjust its emissions according to an agreement, the other country may retaliate - i.e., play tit-for-tat. This is similar to withholding a promised transfer. Given that the first country has reneged on the agreement, the "punisher" will always have an incentive to retaliate.

In terms of allocative efficiency, our analysis paints a fairly optimistic picture. In terms of achieving a socially optimal greenhouse gas stock, however, the inclusion of winners and losers appears to makes the possibility of welfare improving international agreements unlikely. In analyses where all countries are harmed, the main issues concern the international allocation of the costs of abatement and the implementation of the associated set of transfers. In our setting, if the gas stock is too high, the losers must persuade the winners to abate, an action that winner countries will not find desirable. If, indeed, winner countries are primarily rich countries in the high latitudes of the northern hemisphere and loser countries are poor countries in lower latitudes, we will probably not observe income transfers flowing from losers to winners in order to induce winners to voluntarily reduce their emissions. ${ }^{22}$

\section{5. Equilibrium Selection.}

The preceding analysis makes welfare comparisons between the various institutional arrangements under which global warming may arise, but is mute on the issue of equilibrium selection. If one thinks of the global warming game as a simple one shot game, then a non-altruistic government will always choose to play $P$ (partial internalization), while an altruistic government will always

\footnotetext{
${ }^{21}$ Notice that bilateral swaps of this nature would continue to be Pareto improving even when there are multiple winner and loser countries.

${ }^{22}$ Mendelson et. al. [13] develop a gobal impact model that examines country specific impacts of different levels of temperature increase on the welfare of nations. Their conclusions broadly support this scenario.
} 
choose $A$ (full internalization). ${ }^{23}$ This is, however, an oversimplification. It seems plausible to consider the degree of internalization of the externality i.e., the institutional structure - as a strategy in the "global warming game" played between the two countries. If so, the institutional structure which will emerge in the equilibrium of such a game depends on the exact specifications of the game. In fact, governments are clearly free to change their regimes and emissions levels from one period to the next. Given this more plausible definition of the strategy set, the global warming game will unlikely be a one shot game.

Our analysis suggests that, in order to select an equilibrium, one must pay special attention to:

1. The preferences of the two countries. Are the countries altruistic or not?

2. The information sets of the two countries. Do they know each others type as defined by their preferences?

3. The strategy spaces of the two countries. Do they choose policy regimes or actual emissions levels?

4. The appropriate equilibrium concept. Do they take each other's emissions, regimes, or strategies as given?

5. The costs of intervention. Are the costs of regulation prohibitive? If not, how are these costs financed? Who bears these costs?

Although we shall not propose a particular solution to the question of equilibrium selection, it should be clear that any of the nine equilibria studied in this paper may arise as an equilibrium of the global warming game given reasonable assumptions about the structure of such a game.

\section{6. Multiple Winners and Losers.}

So far, we have explored the consequences of there being one representative winner country and one representative loser in a world with global warming.

\footnotetext{
${ }^{23}$ That is if we think of it as a one shot game in which emissions levels are taken as given.
} 
If, alternatively, one considers multiple winners and losers, the picture becomes more complicated. Although we will not provide a detailed analysis of all potential implications of this extension, we will discuss two key issues: (1) the requirements for our prior analysis to be relevant in this more complex world; and (2) the additional insights that this extension might bring.

In this more complex environment, our preceding results do not change under two assumptions:

1. Uniformity of behavior. Each country within a given group - i.e. winners or losers - acts in a similar manner. Each country chooses decentralization, government intervention, etc.

2. Group internalization. Each country fully internalizes the externality effects within its group.

Are these assumptions reasonable? Are they important in a qualitative sense? Geographically clustered countries, which possess similar characteristics, may be inclined to provide the same institutional response to global warming. Loser countries will likely be the poor countries located in tropical or equatorial regions. Winner countries will likely be either rich northern hemisphere countries in Europe and America or the poor Central Asian countries. Although it seems plausible to expect that loser countries will display uniformity of behavior, we should be fairly pessimistic about winner countries behaving uniformly.

The second assumption, group internalization, requires no free riding behavior within group. In the absence of this assumption, each country would have an incentive to emit or abate at the margin up to the point where there individual marginal costs equal marginal benefit. By imposing such an assumption, individual costs will be equated to group benefits.

Relaxing assumptions 1 and 2 may yield some interesting results. Abandoning uniformity of behavior allows one to explore situations where countries with different preferences interact. One may divide the group of winner countries into three subgroups, a subgroup consisting of decentralized countries, another consisting of countries that engage in government intervention and yet another subgroup with altruistic countries. In such a setting, altruism may yield internalization of both negative and positive effects of the global warming externality.

Abandoning group internalization also offers tantalizing possibilities. The groups of winners and losers might be viewed as playing a Nash game within 
the group, with the possibility of generating significant amounts of free riding. Free riding behavior might well be socially desirable in such a context, since winners over emit and losers under emit. If, for example, an increase in free riding behavior helps to eliminate distortions in internal resource allocations, without significant effects on the world stock of greenhouse gas, social welfare may improve. Free riding behavior may prove to be a means of achieving allocative efficiency.

\section{7. Conclusion.}

We have analyzed the "win-lose" scenario in a world with global warming in a simple theoretical model. We compared several institutional arrangements using measures of social welfare and allocative efficiency. Only in the cases of full decentralization and full altruism did the allocations prove to be allocatively efficient. Further only in the fully altruistic case could the social optimal allocation be implemented as a noncooperative equilibrium. Altruism by one country had little clear value and, in the case of full decentralization, the introduction of altruism caused the property of allocative efficiency to be lost.

We have only been able to draw limited conclusions about how the steady state greenhouse gas stock will compare to its socially optimal level. It is clear, however, that abatement is not automatically the correct thing to do. Whether the stock tends to be too large or too small depends crucially upon the institutional arrangement. What is a lot clearer is the nature of the allocative distortions associated with each institutional arrangement. For each equilibrium type, we can characterize gas stock preserving reallocations that are welfare improving.

As a contribution to our basic theoretical understanding of the global warming phenomena, this analysis may not be a straightforward vehicle for policy making. It does, however, offer some tentative suggestions as to the goals that policy might attempt to achieve. We paint a gloomy picture for prospective international policy agreements on the greenhouse gas stock level. Although it seems unlikely that those who benefit and those who are harmed by global warming will reach an accord, our analysis suggests that agreements that take the current greenhouse gas stock as given are more likely to be successful than agreements that attempt to change this stock. 


\section{References}

[1] Climate Network Europe and US. Climate Action Network, "Independent NGO Evaluations of National Plans for Climate Change Mitigation, OECD Countries," Fourth (Interim) Review, June 1996.

[2] Cline, William R., "The Economics of Global Warming," Washington D.C.: Institute for International Economics, June, 1992.

[3] Copeland, Brian R. and M. Scott Taylor, "Trade and Transboundary Pollution," The American Economic Review, September 1995, 85(4), 716-737.

[4] Easterling, William E., Martin L. Parry and Pierre Crosson, "Adapting Future Agriculture to Changes In Climate." In Norman J. Rosenberg, William E. Easterling, Pierre Crosson, and Joel Darmstadter, eds., Greenhouse Warming: Abatement and Adaptation, Washington: Resources For The Future, 1989, 91-104.

[5] Feldman, Daniel L., ed., Global Climate Change and Public Policy, Chicago: Nelson-Hall, 1995.

[6] Haugland, Torlieff, Amund Lunde, and Kjell Roland, "A Review and Comparison of CO2 Taxes in the Nordic Countries," in Organization for Economic Cooperation and Development, Climate Change: Designing a Practical Tax System, Paris, 1992, pgs. 25-54.

[7] Hoeller, Peter and Jonathan Coppel, "Energy Taxation and Price Distortions in Fossil Fuel Markets: Some Implications for Climate Change Policy," in Organization for Economic Cooperation, Climate Change: Designing a Practical Tax System, Paris, 1992, pgs. 185-212.

[8] Intergovernmental Panel on Climate Change, Scientific Assessment of Climate Change: Report Prepared for IPCC by Working Group I, June, 1990, New York: World Meteorological Organization and United Nations Environment Program..

[9] Summary for Policymakers: Scientific-Technical Analysis of Impacts, Adaptations, and Mitigation of Climate Change, IPCC Working Group II, 1995. [WWW page cited May 8, 1996] URL: http://www.unep.ch/ipcc/sumwg.html. 
[10] Martin, Wade E., Robert H. Patrick and Boleslaw Tolwinski, "A Dynamic Game of a Transboundary Pollutant with Asymmetric Players," Journal of Environmental Economics and Management, 1993, 24, 1-12.

[11] Matcheck, Dale C., "National Policies, International Effects: Noncooperative Strategies For Slowing Climate Change," PhD. Dissertation, Cornell University, May 1993.

[12] Mendelsohn, Robert, William D. Nordhaus and Daigee Shaw, "The Impact of Global Warming on Agriculture: A Ricardian Analysis," The American Economic Review, September 1994, 84(2), 753-771.

[13] Mendelsohn, Robert, Wendy Morrison, Micheal E. Schlesinger, and Natalia G. Andronova, "Country Specific Market Impacts of Climate Change," Mimeo 1998.

[14] Murdoch, J. C. and T. Sandler, "The Voluntary Provision of a Pure Public Good: The Case of Reduced CFC Emission and the Montreal Protocol," Journal of Public Economics, 1997, 63, 331-349.

[15] Murdoch, J. C., T. Sandler, and K. Sargent, "A Tale of Two Collectives: Sulfur Versus Nitrogen Oxides Emission Reduction in Europe," Economica, 1997, 64, 281-301.

[16] Nordhaus, William D., "To Slow or Not To Slow: The Economics of the Greenhouse Effect," The Economic Journal, July, 1991, 101, 920-937.

[17] Parry, Martin, Climate Change And World Agriculture, London: Earthscan Publications Limited, 1990.

[18] Sandler, T., "A Game-Theoretic Analysis of Carbon Emissions," in The Political Economy of Environmental Protection, R.D. Congleton ed. 251272, 1996.

[19] Sandler, T. "Global Challenges," Cambridge University Press, 1997.

[20] Schelling, Thomas C., "Some Economics of Global Warming," The American Economic Review, March 1992, 82(1), 1-14.

[21] Schmidt, Karen, "Industrial Countries' Responses To Global Climate Change," Special Report. Washington, D.C.: Environmental And Energy Study Institute, July 1991. 
[22] Shah, Anwar and Bjorn Larsen, "Carbon Taxes, The Greenhouse Effect, and Developing Countries," World Bank Working Paper, 1991. 